\title{
Transient absorption spectra of triplet states and charge carriers of conjugated polymers
}

\author{
H.D. Burrows ${ }^{\mathrm{a}, *}$, M. da G. Miguel ${ }^{\mathrm{a}}$, A.P. Monkman ${ }^{\mathrm{b}}$, I. Hamblett ${ }^{\mathrm{c}}$, S. Navaratnam ${ }^{\mathrm{d}}$

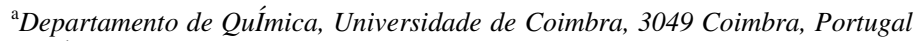 \\ ${ }^{\mathrm{b}}$ Department of Physics, University of Durham, Durham, England, UK \\ ${ }^{\mathrm{c}}$ Department of Chemistry, University of Manchester, Manchester M13 9PL, England, UK \\ ${ }^{\mathrm{d}}$ Multidisciplinary Research and Innovation Centre, North East Wales Institute, Wrexham LL1 2AW, UK
}

Received 31 August 2000; accepted 29 September 2000

\begin{abstract}
The use of pulse radiolysis to study transient species in conjugated polymers in solutions is discussed, with particular reference to poly(2-methoxy-5-(2'-ethylhexoxy)-p-phenylenevinylene) (MEH-PPV). The excited triplet state is specifically generated by energy transfer on radiolysis of benzene solutions in the presence of suitable sensitisers, and its spectrum is reported. The presence of vibronic structure suggests a localised triplet state. By varying the energy of the sensitiser, it is possible to determine the energy of the lowest triplet state. Results are also presented for the triplet-triplet absorptions and energies of five other common $\pi$-conjugated polymers. The MEH-PPV triplet absorption, produced on radiolysis, does not increase linearly with either polymer concentration or radiation dose. This is suggested to be due to the presence of multiple triplet excitations on the isolated polymer chains. Intrachain triplet-triplet annihilation is observed, and is seen to lead to delayed fluorescence. Spectra are also reported for the positive and negative charge carriers of MEH-PPV and the other polymers specifically produced by pulse radiolysis of the polymers in chloroform or tetrahydrofuran solutions. (C) 2001 Elsevier Science B.V. All rights reserved.
\end{abstract}

Keywords: Conjugated polymers; Pulse radiolysis; Triplet excited states; Charge carriers

\section{Introduction}

Although efficient electroluminescence from conjugated polymers was first reported over 25 years ago [1], the current intense activity in this area has derived largely from the observation of high yield emission from light emitting diodes (LEDs) based on poly $(p-$ phenylenvinylene) (PPV) and its derivatives $[2,3]$. A variety of other families of luminescent conjugated polymers have since been developed, and these now

\footnotetext{
* Corresponding author. Tel.: +351-39-852080; fax: +351-239827703.

E-mail address: burrows@ci.uc.pt (H.D. Burrows).
}

constitute a technologically important class of materials. Polymer-based LED display systems are already a reality [4], and the potential market for these materials is enormous. This is likely to grow even further if the development of an all-polymer laser based on these systems [5] proves successful.

Both the synthesis and applications of luminescent conjugated polymers have been extensively reviewed [5-8], and there is a general understanding of the mechanism of electroluminescence in conjugated organic systems, involving generation of positive and negative charge carriers by hole or electron injection from electrodes, followed by charge recombination to produce excited states [9]. However, their 


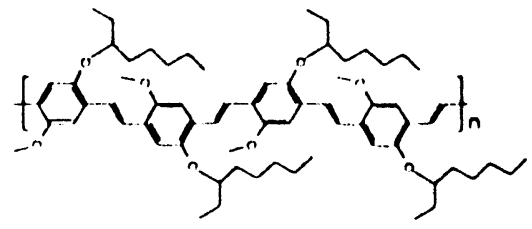

poly(2-methoxy-5-(2'-ethylhexyloxy)-p-phenylenevinylene

(MEH-PPV)

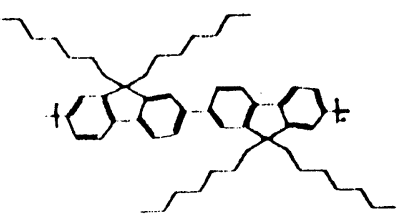

poly(dioctylfluorene)

PFO

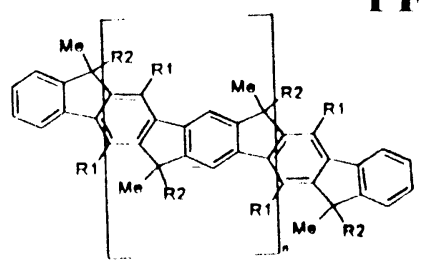

methyl-poly (p-phenylene)

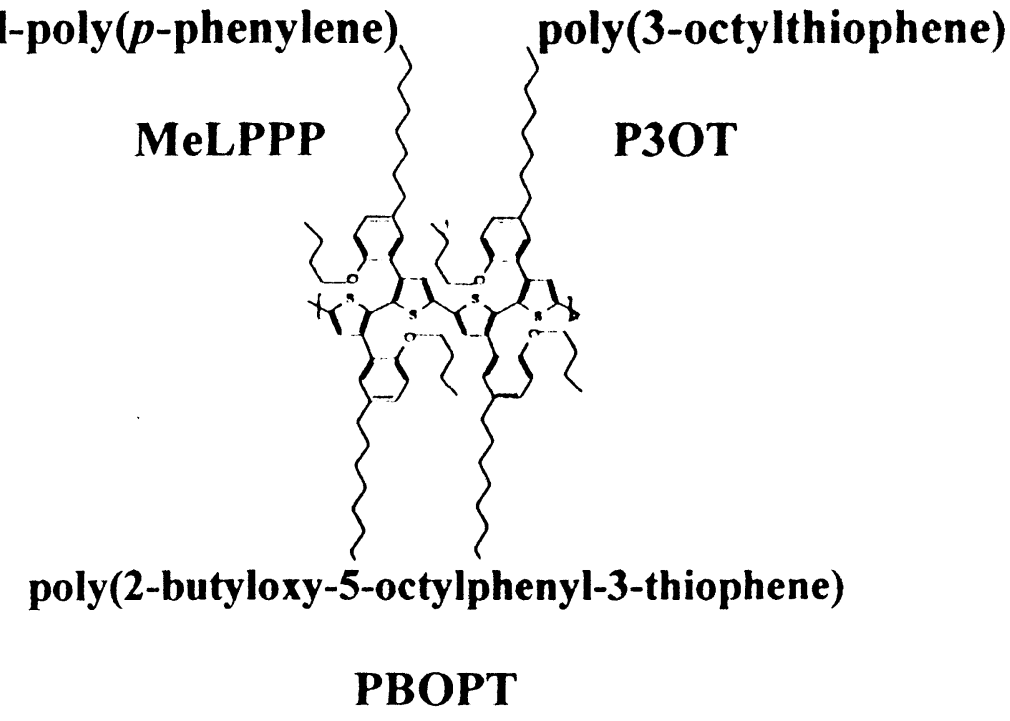

poly(pyridine)

PPY

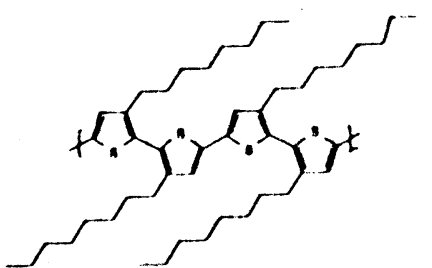

poly(3-octylthiophene) 
optical and photophysical properties are complex, and difficulties exist in assigning the different transient species observed over a wide range of time domains (from femtoseconds to seconds) in photoluminescence, photoinduced and electroinduced absorption spectral measurements [10-13]. In addition, conflicting opinions exist on the strength of coupling in the excited states and charge carriers, with descriptions given in terms of both molecular exciton [14] and one-electron semiconductor band [15] models. There is, thus, the need for an unambiguous technique for preparation and characterisation of these transient species to help in their assignment and to provide an experimental base for understanding the extent of electron-electron correlation.

Conjugated polymers are normally expected to have a non-degenerate (singlet) ground state. Charge recombination will produce both singlet and triplet excited states, and for the case of strong coupling, spin statistics dictate that these will be produced in the ratio $1: 3$ [16]. Since only the singlet is normally luminescent, this will greatly reduce the efficiency of these systems when they are used as light emitting devices. Some of this triplet excitation energy can be captured by energy transfer, and reemitted by appropriate acceptors [17], but efficient use of this requires information on the polymer triplet energies. Unfortunately, the only unambiguous determination of triplet energy of a $\pi$-conjugated polymer has been from the phosphorescence of a ladder-type poly( $p$-phenylene) $[18,19]$. No other well-authenticated case of phosphorescence from a conjugated polymer has been given, and it is important to develop other techniques to determine reliable triplet energies.

Pulse radiolysis has proved to be an excellent technique for the selective generation and study of excited states and charged species [20]. This involves passing an intense, short-lived pulse of high-energy radiation through a sample and studying the resultant non-equilibrium situation by transient absorption spectroscopy, or some other analytical technique. The radiation chemistry of solutions is dominated by the most prevalent species, the solvent [21]. By appropriate choice of conditions, it is possible to specifically produce either excited states or charged species. We have previously used this method to look at the lowest excited triplet states [22-25] and charged species $[23,26]$ of some conjugated organic polymers in solution. In this paper we extend this study to include many of the most commonly used polymers in electroluminescent devices.

\section{Experimental}

Regioregular poly(pyridine) (PPY) was synthesised as described elsewhere [27]. The other conjugated polymers, whose structures are shown in Fig. 1, were generous gifts from Covion (MEH-PPV), Prof. U. Scherf (MeLPPP and PFO) and Prof. M. Anderson (polythiophenes). THF was dried and distilled from calcium hydride. Other reagents were of the purest grade available and were used without further treatment.

Polymers were dissolved using mechanical stirring, and the solutions degassed by passing argon for $30 \mathrm{~min}$ before transferring to the pulse radiolysis set-up.

Pulse radiolysis experiments were carried out at the Free Radical Research Facility of the Paterson Institute for Cancer Research (Manchester, UK) using, typically, $50 \mathrm{~ns}$, ca $7.5 \mathrm{~Gy}$ pulses from a $10 \mathrm{MeV}$ electron linear accelerator. Transient absorption difference spectra were observed using a Xenon source and gated diode array or photomultiplier for detection. General details have been reported $[22,28]$.

\section{Results and discussion}

\subsection{Triplet state studies}

Triplet-triplet energy transfer following pulse radiolysis of solutes in aromatic solvents, such as benzene $(\mathrm{Bz})$, in the presence of appropriate energy sensitisers is an excellent technique for the selective creation and study of triplet excited states of organic molecules [29,30]. The sensitiser (A) accepts energy from the short-lived benzene excited states and transfers it to the solute $(\mathrm{S})$. The general reaction scheme is

$$
\begin{aligned}
& \mathrm{Bz} \rightarrow{ }^{1} \mathrm{Bz}^{*}+{ }^{3} \mathrm{Bz}^{*} \\
& { }^{1} \mathrm{Bz}^{*} \rightarrow{ }^{3} \mathrm{Bz}^{*} \\
& { }^{3} \mathrm{Bz}^{*}+\mathrm{A} \rightarrow \mathrm{Bz}+{ }^{3} \mathrm{~A}^{*}
\end{aligned}
$$




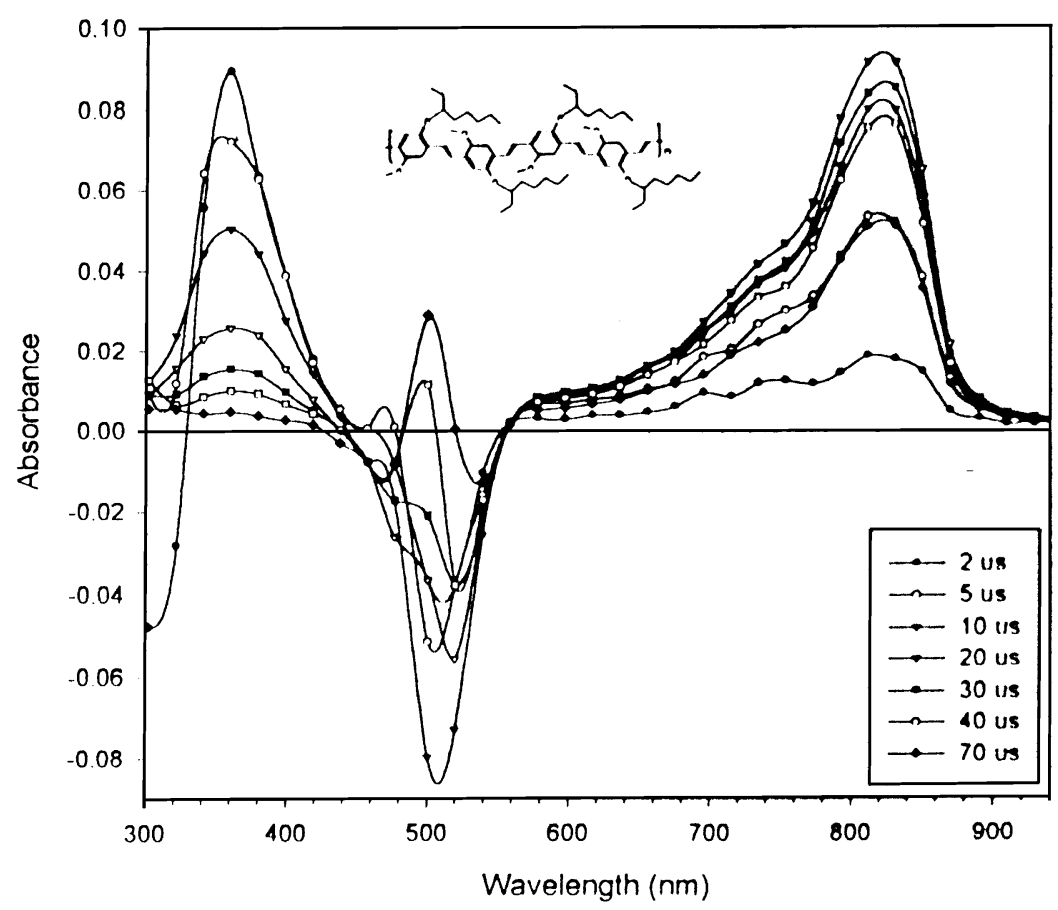

Fig. 2. Transient absorption spectra observed on pulse radiolysis of argon-saturated solutions of MEH-PPV and biphenyl in benzene. Note the grow-in of the ${ }^{3} \mathrm{MEH}-\mathrm{PPV}^{*}$ band at $830 \mathrm{~nm}$, bleaching of ground state absorption at $530 \mathrm{~nm}$, and the initial biphenyl triplet-triplet absorption at $360 \mathrm{~nm}$. Reprinted from A.P. Monkman, H.D. Burrows, M. da G. Miguel, I. Hamblett and S. Navaratnam, Chem. Phys. Lett. 307 (1999) 303-309, Copyright (1999) with permission from Elsevier Science.

${ }^{3} \mathrm{~A}^{*}+\mathrm{S} \rightarrow \mathrm{A}+{ }^{3} \mathrm{~S}^{*}$

where $[\mathrm{Bz}] \gg[\mathrm{A}] \gg[\mathrm{S}]$

We have shown that this technique can readily be applied to the study of the triplet state of conjugated polymers [22-25]. As a typical case,

Table 1

Triplet-triplet absorption maxima and lowest triplet state energies for conjugated polymers obtained by pulse radiolysis in benezene solutions in the presence of sensitisers

\begin{tabular}{lll}
\hline Polymer & $\begin{array}{l}\mathrm{T}_{1}-\mathrm{T}_{n} \\
\text { absorption } \\
\text { maximum } \\
\text { in nm (eV) }\end{array}$ & \\
\hline MEH-PPV & $830(1.50)$ & $10500(1.30)$ \\
MeLPPP & $925(1.34)$ & $17500(2.15)$ \\
PFO & $750(1.65)$ & $18500(2.30)$ \\
P3OT & $825(1.50)$ & $14500(1.80)$ \\
PBOPT & $900(1.38)$ & $13000(1.60)$ \\
PPY & $590(2.10)$ & $19500(2.40)$ \\
\hline
\end{tabular}

we will consider poly(2-methoxy-5-( $2^{\prime}$-ethylhexoxy)$p$-phenylenevinylene) (MEH-PPV). Pulse radiolysis of an argon-saturated solution of this polymer $(25 \mathrm{mg} / \mathrm{l})$ in benzene in the presence of biphenyl leads to initial formation of an absorption at $360 \mathrm{~nm}$ assigned to the biphenyl triplet state [29,31]. The decay of this is accompanied by the grow-in of a new absorption at $830 \mathrm{~nm}$, assigned to the MEH-PPV triplet state [22], and corresponding bleaching of the ground state MEH-PPV absorption at $530 \mathrm{~nm}$. These spectral changes are illustrated in Fig. 2. The absorption spectrum of the triplet state of MEH-PPV is very similar to what has been reported for thin films of other PPV derivatives at low temperatures using photoinduced absorption [10,32]. There is a small blue-shift (ca $50 \mathrm{~nm}, 0.1 \mathrm{eV}$ ) in the absorption maximum in solution compared with thin films. Triplet-triplet absorption spectra for the other polymers in benzene solutions have been determined in the same way, and the relevant data are summarised in Table 1.

Although poorly resolved, the triplet-triplet 
Table 2

Kinetics of formation and decay of MEH-PPV triplet states by energy transfer from biphenyl as functions of radiation dose

\begin{tabular}{|c|c|c|c|c|}
\hline \multirow[t]{2}{*}{ Dose $(\mathrm{nC})^{\mathrm{a}}$} & \multicolumn{2}{|l|}{ Formation } & \multicolumn{2}{|l|}{ Decay } \\
\hline & $k_{\mathrm{obs}}\left(10^{4} \mathrm{~s}^{-1}\right)$ & $k_{2}^{\mathrm{b}}\left(10^{11} \mathrm{M}^{-1} \mathrm{~s}^{-1}\right)$ & $k_{\mathrm{T}}\left(10^{4} \mathrm{~s}^{-1}\right.$ & $2 \gamma / \epsilon l\left(10^{4} \mathrm{~s}^{-1}\right)$ \\
\hline 0.150 & 5.50 & 1.97 & 0.97 & - \\
\hline 0.285 & 7.18 & 1.32 & 1.03 & - \\
\hline 0.675 & 11.2 & 0.91 & 1.12 & - \\
\hline 1.395 & 20.8 & 0.83 & 1.20 & $0.76^{\mathrm{c}}$ \\
\hline 2.935 & 35.3 & 0.67 & 1.34 & $1.16^{\mathrm{c}}$ \\
\hline
\end{tabular}

a $\mathrm{SEC}$ reading in $\mathrm{nC} .1 \mathrm{nC} \approx 11-12 \mathrm{~Gy}$.

${ }^{\mathrm{b}}$ Calculated as described in the text.

c Analysed as competing first- and second-order kinetics.

absorption spectrum of MEH-PPV shows definite vibronic structure with spacing ca $1600 \mathrm{~cm}^{-1}$ $(200 \mathrm{meV})$, which is probably associated with $\mathrm{C}=\mathrm{C}$ stretch modes [22]. The ground-state absorption spectrum shows no such structure [33], suggesting that the triplet state has a more localised character than the ground state.

The species responsible for this new absorption is strongly quenched by molecular oxygen in a bimolecular process $\left(k=2.5 \times 10^{9} \mathrm{M}^{-1} \mathrm{~s}^{-1}\right)$. This has been shown by time-resolved luminescence measurements to lead to formation of singlet molecular oxygen, with $\Phi_{\Delta}=0.025$ [22], via the energy transfer reaction

${ }^{3} \mathrm{~S}^{*}+\mathrm{O}_{2}\left({ }^{3} \Sigma_{\mathrm{g}}^{-}\right) \rightarrow \mathrm{S}+{ }^{1} \mathrm{O}_{2}^{*}\left({ }^{1} \Delta_{\mathrm{g}}\right)$

Singlet oxygen formation, and subsequent reaction with the conjugated polymer is likely to be an important mechanism for failure of non-encapsulated polymer LEDs $[22,34]$. The quantum yield for singlet oxygen formation is, within experimental error, identical to that determined for $\mathrm{S}_{1} \rightarrow \mathrm{T}_{1}$ intersystem crossing in MEH-PPV in benzene solution using photoacoustic calorimetry [35].

In addition to the use of energy transfer to populate triplet excited states of conjugated polymers and to obtain their transient absorption spectra, we can also use it to determine energies of their lowest triplet states $[22,24,29,30]$. A series of measurements are made using different sensitisers (A) to see which will transfer triplet energy to the polymer. When $E\left({ }^{3} \mathrm{~A}^{*}\right)<E\left({ }^{3} \mathrm{~S}^{*}\right)$, energy transfer is no longer possible and an upper limit can be placed on the triplet energy of the polymer. Using the sensitisers available to us, with well-characterised triplet energies [31], it is possible to estimate the triplet energy of the polymer to better than $\pm 0.1 \mathrm{eV}\left(800 \mathrm{~cm}^{-1}\right)$ in the majority of cases. The validity of the method has been confirmed by measurements on the ladder type methyl-poly $(p$ phenylene), MeLPPP. The energy of the lowest triplet state of this has been determined by phosphorescence to be $16500 \mathrm{~cm}^{-1}(2.05 \mathrm{eV})$ in the solid state at $77 \mathrm{~K}$ [18]. Using the energy transfer technique we have determined a triplet energy of $17350 \pm 800 \mathrm{~cm}^{-1}$ $(2.15 \pm 0.1 \mathrm{eV})$ for MeLPPP in benzene solution at room temperature [24]. Given the difference in conditions, the agreement is excellent. We have applied this technique to the determination of the triplet energies of a variety of other polymers. Details are given elsewhere [25], and data are also summarised in Table 1.

\subsection{Delayed fluorescence}

In our initial studies on the triplet-triplet absorption of MEH-PPV using naphthalene or biphenyl triplet state as the sensitiser, attempts were made to determine the molar absorption coefficient [22]. However, the absorbance showed an almost exponential dependence upon polymer concentration. A possible explanation for this behaviour comes from the fact that in these experiments, the molar concentration of triplet state of the sensitiser (up to $5 \mu \mathrm{M}$ ) was much greater than that of the polymer $\left(\approx 3 \times 10^{-8} \mathrm{M}\right)$, and under these conditions it is possible to have more than one triplet state per polymer chain. Support for this idea comes from studies of the effect of radiation dose on the rates of formation and decay of MEH-PPV triplet state using 
biphenyl $\left(\Phi_{2}\right)$ as sensitiser. The formation rate corresponds to the process

$$
{ }^{3} \Phi_{2}^{*}+\mathrm{MEH}-\mathrm{PPV} \rightarrow \Phi_{2}+{ }^{3} \mathrm{MEH}-\mathrm{PPV}^{*}
$$

and for our experiments the pseudo-first-order conditions $\left[{ }^{3} \Phi_{2}^{*}\right] \gg[\mathrm{MEH}-\mathrm{PPV}]$ hold. Pseudo-first-order rate constants $\left(k_{\text {obs }}\right)$ were determined from transient absorption data for the grow-in of the triplet state (Table 2). From these, second-order rate constants were calculated using the biphenyl triplet concentrations calculated from the absorbance and known [31] biphenyl molar absorption coefficient, and are also presented. The values are close to what would be expected for a diffusion controlled collisional process between the polymer (molecular weight $1.6 \times 10^{6}$ ) and biphenyl triplet in benzene solution $\left(k_{\text {diff }} \approx 2 \times\right.$ $10^{11} \mathrm{M}^{-1} \mathrm{~s}^{-1}$ [36]). However, the rate decreases on increasing the radiation dose. Two effects may be involved. At high dose, biphenyl triplet-triplet annihilation occurs, as seen in separate experiments in the absence of polymer, and this reduces the number of triplets which can energy transfer to the polymer. However, also, under our conditions, more than one triplet can be transferred to each polymer chain

${ }^{3} \Phi_{2}^{*}+$ MEH-PPV $\rightarrow \Phi_{2}+{ }^{3}$ MEH-PPV*

${ }^{3} \Phi_{2}^{*}+{ }^{3} \mathrm{MEH}-\mathrm{PPV}^{*} \rightarrow \Phi_{2}+{ }^{3} \mathrm{MEH}-\mathrm{PPV}^{* *}$

${ }^{3} \Phi_{2}^{*}+{ }^{3} \mathrm{MEH}^{-\mathrm{PPV}^{* *}} \rightarrow \Phi_{2}+{ }^{3} \mathrm{MEH}^{\mathrm{PPV}}{ }^{* * *} \ldots$

However, as individual polymer chains start having more triplet excitations, less sites are available, and the rate of energy transfer will decrease. The kinetics will be similar to those previously discussed for solubilisation of probe molecules in other large aggregates, such as micelles [37,38]. There is also likely to be a limit to the number of sites to which energy transfer is possible. Evidence for this comes from the saturation of the MEH-PPV triplet-triplet absorption at high radiation doses when sensitised by biphenyl [35]. We estimate that for the polymer sample used this corresponds to roughly a maximum of 30 triplets per chain. The same effect is probably also responsible for the non-linear dependence of the triplettriplet absorption with polymer concentration described earlier. The transient absorption spectra are, however, independent of dose, and hence triplet population per chain, indicating that the triplet states do not interact, in agreement with their localised character.

If polymer chains can carry more than one triplet excitation, the intriguing possibility exists of triplettriplet reactions. At the polymer concentrations used in these experiments $\left(<5 \times 10^{-8} \mathrm{M}\right)$, the time between collision of two polymer molecules is several milliseconds, and the chains are essentially isolated within the lifetime of the excited triplet states. The decay of the MEH-PPV triplet-triplet absorption was studied as a function of radiation dose (Table 2). At low doses, first-order kinetics was observed. However, at higher doses the decay could no longer be fitted to a single exponential, but instead followed the rate law

$$
\begin{aligned}
& \mathrm{d}\left[{ }^{3} \mathrm{MEH}-\mathrm{PPV}^{*}\right] / \mathrm{d} t=-k_{\mathrm{T}}\left[{ }^{3} \mathrm{MEH}-\mathrm{PPV}^{*}\right] \\
& -\gamma\left[^{3} \mathrm{MEH}-\mathrm{PPV}^{*}\right]^{2}
\end{aligned}
$$

with the second-order term increasing in both magnitude and amplitude with dose (Table 2). This secondorder term must correspond to intrachain triplettriplet annihilation [36], which can produce either excited singlet or triplet states $[39,40]$ in the reactions

$\mathrm{T}_{1}+\mathrm{T}_{1} \leftrightarrow{ }^{1,3,5}\left(\mathrm{~T}_{1} \cdots \mathrm{T}_{1}\right) \leftrightarrow \begin{aligned} & \mathrm{S}_{1}+\mathrm{S}_{0} \\ & \mathrm{~T}_{1}+\mathrm{S}_{0}\end{aligned}$

The excited singlet state can then lose its energy by emitting delayed fluorescence (DF). This has been observed following pulse radiolysis of argonsaturated solutions of MEH-PPV, and other conjugated polymers, in benzene in the presence of biphenyl $[24,36]$. As expected for DF, the rate of decay parallels the decay of the triplet state, and is completely quenched by the presence of molecular oxygen.

\subsection{Positive charge carriers}

One-electron oxidation species of conjugated polymers have previously been reported based on results of chemical oxidation [41-44]. However, although valuable information has been obtained from these studies, the relatively long timescale between mixing of reagents and observation of spectra leads to the possibility of multistep processes and observation of higher oxidation states. Radiolysis of solutes in 
(a)

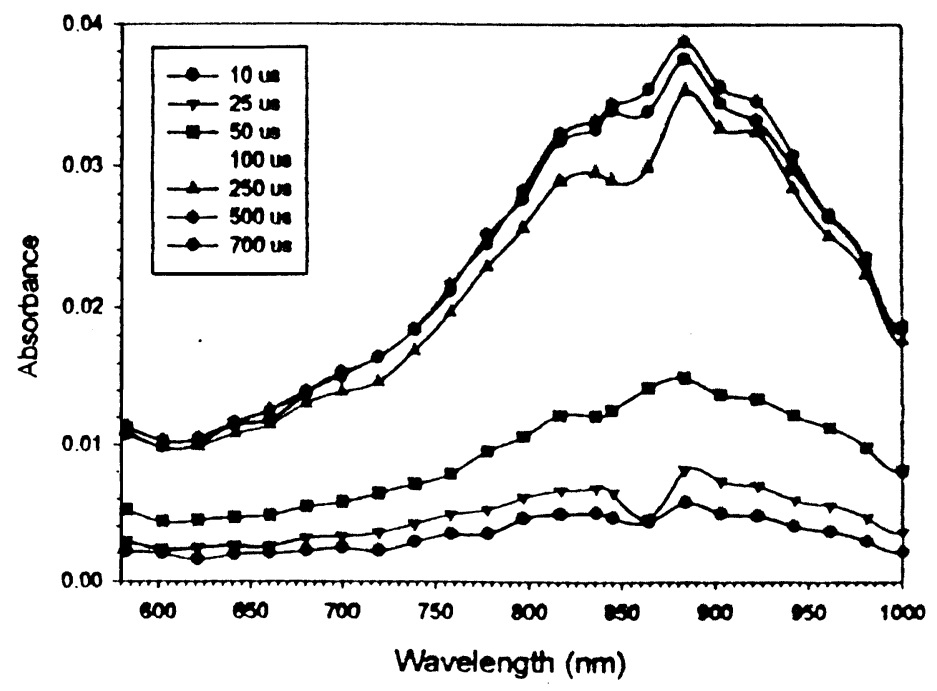

(b)

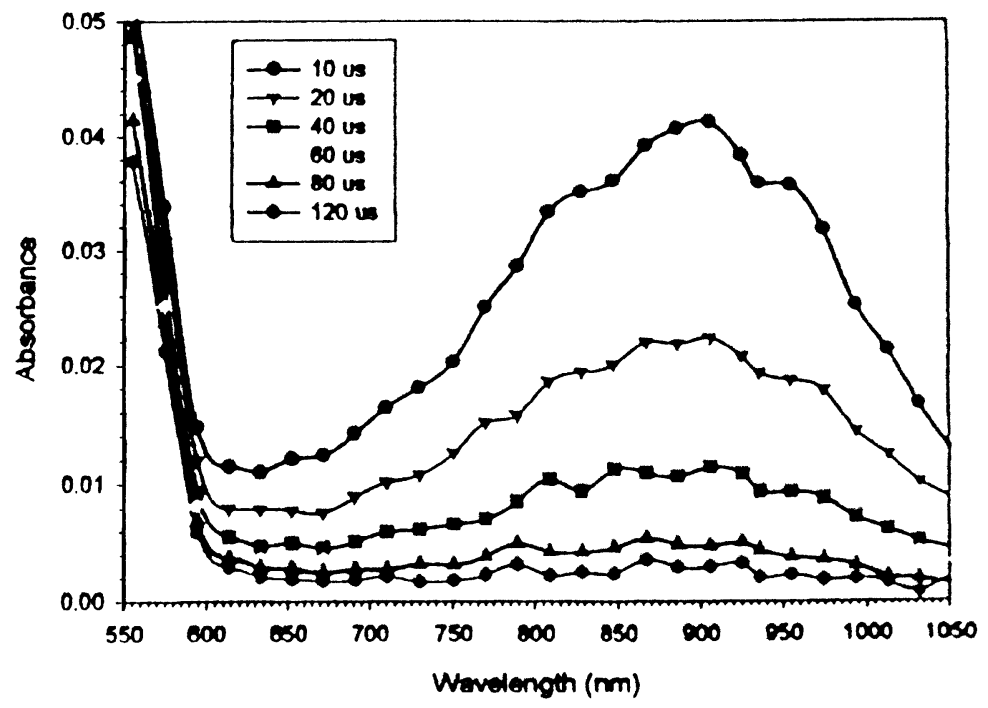

Fig. 3. Transient absorption spectra of: (a) positive charge carrier of MEH-PPV produced on pulse radiolysis of argon saturated chloroform solutions; and (b) negative charge carrier of MEH-PPV produced on pulse radiolysis of argon saturated THF solutions.

chloroform solution has been shown $[45,46]$ to be a good route for specifically generating their one-electron oxidised species, $\mathrm{S}^{++}$, in the reaction sequence

$2 \mathrm{CHCl}_{3} \rightarrow \mathrm{CHCl}_{3}^{++}+{ }^{\cdot} \mathrm{CHCl}_{2}+\mathrm{Cl}^{-}$

$\mathrm{CHCl}_{3}^{++}+\mathrm{S} \rightarrow \mathrm{CHCl}_{3}+\mathrm{S}^{\cdot+}$
We have shown that this can be used to unambiguously prepare the positive charge carriers of conjugated polymers $[23,26]$. We will take MEH-PPV as a typical case. Following pulse radiolysis of an argonsaturated solution of MEH-PPV in chloroform, a new absorption is seen to grow in at $870 \mathrm{~nm}(1.43 \mathrm{eV})$ (Fig. 3(a)). The transient absorption spectrum is 
Table 3

Absorption maxima of positive $\left(\mathrm{P}^{+}\right)$and negative $\left(\mathrm{P}^{-}\right)$charge carriers produced by pulse radiolysis of argon saturated solutions of polymers in chloroform $\left(\mathrm{P}^{+}\right)$or $\mathrm{THF}\left(\mathrm{P}^{-}\right)$

\begin{tabular}{lll}
\hline Polymer & $\mathrm{P}^{+}$in $\mathrm{nm}(\mathrm{eV})$ & $\mathrm{P}^{-}$in $\mathrm{nm}(\mathrm{eV})$ \\
\hline MEH-PPV & $870(1.43), \geq 1500(\leq 0.8)$ & $900(1.38)$ \\
MeLPPP & $650(1.91)$ & $650(1.91)$ \\
PFO & $460(2.70)^{\mathrm{a}}$ & $430(2.88)^{\mathrm{b}}$ \\
P3OT & $800(1.55)$ & $800(1.55)$ \\
PBOPT & $\mathrm{c}$ & $885(1.40)$ \\
PPY & - & $480,890(3.64,1.40)^{\mathrm{d}}$ \\
\hline
\end{tabular}

${ }^{\text {a }}$ In tetrachlorethylene.

b Second short-lived transient absorption also observed at $595 \mathrm{~nm}$, but may be due to other species.

c Not determined.

${ }^{\mathrm{d}}$ In formic acid.

assigned to the positive charge carrier MEH-PPV ${ }^{+}$, and is a similar to that previously reported for the radical cations of various $p$-phenylenevinylene oligomers obtained by chemical oxidation $[42,44]$. Theoretical studies on the positive charge carrier (polaron) state of oligo(phenylenevinylenes) [47] suggest that they should show two subgap electronic transitions. A second, weaker feature is observed experimentally above $1500 \mathrm{~nm}$ [23], but is difficult to characterise as it is at the spectral limit of our detection system.

The absorption spectra of the one-electron oxidised forms of a number of other conjugated polymers have also been obtained by pulse radiolysis of argon-saturated chloroform solutions, and data are summarised in Table 3.

\subsection{Negative charge carriers}

The one-electron reduced species of a number of conjugated oligomers and polymers have been prepared by chemical reduction using alkali metals $[42,44,48,49]$, and have helped assign their negative charge carriers. However, these systems are susceptible to both ion pair formation [50,51] and dimerization of the negative species [52], which will affect both their spectral and chemical properties. In contrast, radiolysis of tetrahydrofuran (THF) has been shown to produce predominantly solvated electrons and ions, with a very small concentration of short-lived excited states $[53,54]$. In the presence of solutes, the main product is the one-electron reduced species produced by solvated electron addition. In Fig. 3(b), we show the spectrum of the one-electron reduced form of MEH-PPV, produced by pulse radiolysis in THF solution in the reaction

$\mathrm{e}_{\text {solv }}^{\cdot-}+$ MEH-PPV $\rightarrow$ MEH-PPV ${ }^{--}$

This shows an intense transient absorption around $900 \mathrm{~nm}(1.38 \mathrm{eV})$, which is fully formed within $1 \mu \mathrm{s}$. The absorption maximum is in good agreement with theoretical predictions [55]. In agreement with this assignment, the transient decays fairly rapidly in the presence of oxygen due to a chemical reaction, as expected for a typical organic radical anion [56]. This reactivity of the negative charge carrier of the conjugated polymer has implications in relation to their cathodic stability [57].

The one-electron reduced species from MEH-PPV has also been prepared by pulse radiolysis in benzonitrile solution [26]. The spectrum is similar, but appears to show a small solvent shift.

We have prepared the negative charge carriers of a range of other conjugated polymers and summarise the data in Table 3.

\section{Conclusions}

Pulse radiolysis is shown to be a powerful technique for the specific generation and characterisation of triplet states and charged species of conjugated organic polymers in solution. In general, the triplet state absorption maxima in their electronic absorption spectra are close to those observed in photoinduced absorption experiments on thin films. The spectra show some structure, suggesting that the excited states are relatively localised. It is possible to produce more than one triplet state per polymer chain, leading to the possibility of obtaining delayed fluorescence via triplet-triplet annihilation. The absorption spectra observed for the positive and negative charge carriers of each conjugated polymer are, in general, very similar. Comparison with the behaviour of small alternant aromatic compounds [58] suggests that these transition, too, are relatively localised within the polymer structure. 


\section{Acknowledgements}

We are indebted to the people mentioned in the Experimental Section for their generous supply of polymer samples, the Paterson Institute for Cancer Research Free Radical Research Facility for access to the pulse radiolysis system and Dr Donald Allan for helping things to run so smoothly. Financial support from PRAXIS XXI (project 2/2.1/QUI/411/ 94), EPSRC (GR/M86040) and the British Council/ CRUP (project B-2/99) is gratefully acknowledged.

\section{References}

[1] R.H. Partridge, U.K. Pat. 74/44704, Chem. Abstr. 86 (1974) 11261.

[2] J.H. Burroughes, D.D.C. Bradley, A.R. Brown, R.N. Marks, K. Mackay, R.H. Friend, P.L. Burn, A.B. Holmes, Nature 347 (1990) 539.

[3] D. Braun, A.J. Heeger, Appl. Phys. Lett. 58 (1991) 1982.

[4] R.J. Visser, Philips J. Res. 51 (1998) 467.

[5] F. Hide, M.A. Díaz-Garciá, B.J. Schwartz, A.J. Heeger, Acc. Chem. Res. 30 (1997) 430.

[6] A. Kraft, A.C. Grimsdale, A.B. Holmes, Angew. Chem. Int. Ed. 37 (1998) 402.

[7] R.H. Friend, R.W. Gymer, A.B. Holmes, J.H. Burroughes, R.N. Marks, C. Taliani, D.D.C. Bradley, D.A. Dos Santos, J.L. Brédas, M. Löglund, W.R. Salaneck, Nature 397 (1999) 121.

[8] T. Yamamoto, Bull. Chem. Soc. Jpn 72 (1999) 621.

[9] J. Salbeck, Ber. Bunsenges. Phys. Chem. 100 (1996) 1667.

[10] R.H. Friend, D.D.C. Bradley, P.D. Townsend, J. Phys. D: Appl. Phys. 20 (1987) 1367.

[11] N.S. Sariciftci (Ed.), Primary Photoexcitations in Conjugated Polymers. Molecular Exciton versus Semiconductor Band Model World Scientific, Singapore, 1997.

[12] N.T. Harrison, G.R. Hayes, R.T. Phillips, R.H. Friend, Phys. Rev. Lett. 77 (1996) 1881.

[13] S.V. Frolov, M. Ozaki, W. Gellermann, K. Oshino, Z.V. Vardeny, Phys. Rev. Lett. 78 (1997) 729.

[14] U. Rauscher, H. Bässler, D.D.C. Bradley, M. Hennecke, Phys. Rev. B 42 (1990) 9830.

[15] W.P. Su, J.R. Schreiffer, A.J. Heeger, Phys. Rev. Lett. 42 (1979) 1698.

[16] M.A. Baldo, D.F. O’Brien, M.E. Thompson, S.R. Forrest, Phys. Rev. B 60 (1999) 14422.

[17] M.A. Baldo, M.E. Thompson, S.R. Forrest, Nature 403 (2000) 750.

[18] Yu.V. Romanovskii, A. Gerhard, B. Schweitzer, U. Scherf, R.I. Personov, H. Bässler, Phys. Rev. Lett. 84 (2000) 1027.

[19] Yu.V. Romanovskii, H. Bässler, Chem. Phys. Lett. 326 (2000) 51.

[20] J.H. Baxendale, M.A.J. Rodgers, Chem. Soc. Rev. 7 (1978) 235.
[21] A.J. Swallow, in: Farhataziz, M.A.J. Rodgers (Eds.), Radiation Chemistry, Principles and Applications, VCH, Weinheim, 1987.

[22] A.P. Monkman, H.D. Burrows, M. da G. Miguel, I. Hamblett, S. Navaratnam, Chem. Phys. Lett. 307 (1999) 303.

[23] A.P. Monkman, H.D. Burrows, L.E. Horsburgh, L.J. Hartwell, M. da G. Miguel, I. Hamblett, S. Navaratnam, Proc. SPIE 3797 (1999) 109.

[24] A.P. Monkman, H.D. Burrows, I. Hamblett, S. Navaratnam, U. Scherf, C. Schmitt, Chem. Phys. Lett. 327 (2000) 111.

[25] A.P. Monkman, H.D. Burrows, L.J. Hartwell, L.E. Horsburgh, I. Hamblett, S. Navaratnam, submitted for publication.

[26] H.D. Burrows, M. da G. Miguel, A.P. Monkman, L.E. Horsburgh, I. Hamblett, S. Navaratnam, J. Chem. Phys. 112 (2000) 3082 .

[27] L.E. Horsburgh, A.P. Monkman, in preparation.

[28] J. Butler, B.W. Hodgson, B.M. Hoey, E.J. Land, J.S. Lea, E.J. Lindley, F.A.P. Rushton, A.J. Swallow, Radiat. Phys. Chem. 34 (1989) 633.

[29] E.J. Land, Proc. R. Soc. A 305 (1968) 457.

[30] R.V. Bensasson, E.J. Land, T.G. Truscott, Excited States and Free Radicals in Biology and Medicine, Oxford University Press, Oxford, 1993.

[31] S.L. Murov, I. Carmichael, G.L. Hug, Handbook of Photochemistry, 2nd ed., Marcel Dekker, New York, 1993.

[32] X. Wei, B.C. Hess, Z.V. Vardeny, F. Wudl, Phys. Rev. Lett. 68 (1992) 666.

[33] T.-Q. Nguyen, V. Doan, B.J. Schwartz, J. Chem. Phys. 110 (1999) 4068.

[34] R.D. Scurlock, B. Wang, P.R. Ogilby, J.R. Sheats, R.L. Clough, J. Am. Chem. Soc. 117 (1995) 10194.

[35] H.D. Burrows, A.P. Monkman, M. da G. Miguel, J. Seixas de Melo, I. Hamblett, S. Navaratnam, in preparation.

[36] A.P. Monkman, H.D. Burrows, I. Hamblett, S. Navaratnam, submitted for publication.

[37] M. Tachiya, in: G.R. Freeman (Ed.), Kinetics of Nonhomogeneous Processes, Wiley, New York, 1987, pp. 575-649.

[38] G. Rothenberger, P.R. Infelta, in: M. Grätzel, K. Kalyanasundaram (Eds.), Surfactant Science Series: Kinetics and Catalysis in Microheterogeneous Systems, Marcel Dekker, New York, 1991, pp. 49-62.

[39] J.B. Birks, Phys. Lett. 24A (1967) 479.

[40] C.E. Swenberg, N.E. Geacintov, in: J.B. Birks (Ed.), Organic Molecular Photophysics, vol.1, Wiley-Interscience, London, 1973, pp. 489-564.

[41] C.W. Spangler, T.J. Hall, L.S. Sapochak, P-K. Liu, Polymer 30 (1989) 1166.

[42] M. Deussen, H. Bässler, Chem. Phys. 164 (1992) 247.

[43] A. Sakamoto, Y. Furukawa, M. Tasumi, J. Phys. Chem. 98 (1994) 4635.

[44] R. Schenk, H. Gregorius, K. Müllen, Adv. Mater. 3 (1991) 492.

[45] W. Hamill, in: E.T. Kaiser, L. Kevan (Eds.), Radical Ions, Wiley-Interscience, New York, 1968, pp. 321-416.

[46] H.D. Burrows, D. Greatorex, T.J. Kemp, J. Phys. Chem. 76 (1972) 20.

[47] J. Cornil, D. Beljonne, J.L. Brédas, J. Chem. Phys. 103 (1995) 834. 
[48] Y. Furukawa, A. Sakamoto, M. Tasumi, Macromol. Symp. 101 (1996) 95.

[49] J.M. Oberski, A. Greiner, H. Bässler, Chem. Phys. Lett. 184 (1992) 391.

[50] D.G. Powell, E. Warhurst, Trans. Faraday Soc. 58 (1962) 953.

[51] N. Hirota, J. Am. Chem. Soc. 89 (1967) 32.

[52] N. Hitota, S. Weissman, J. Am. Chem. Soc. 86 (1964) 2538.

[53] J.H. Baxendale, D. Beaumond, M.A.J. Rodgers, Trans. Faraday Soc. 66 (1970) 1996.
[54] F.Y. Jou, L.M. Dorfman, J. Chem. Phys. 58 (1973) 4715.

[55] S. Karabunarliev, M. Baumgarten, N. Tyulkov, K. Müllen, J. Phys. Chem. 98 (1994) 11892.

[56] J.F. Garst, in: J.K. Kochi (Ed.), Free Radicals, vol. 1, Wiley, New York, 1973 (p. 509).

[57] H.D. Burrows, A.P. Monkman, M. da G. Miguel, I. Hamblett, S. Navaratnam, submitted for publication.

[58] W.I. Aacbersberl, G.J. Hoijtink, E.C. Mackor, P.L. Weijland, J. Chem. Soc. (1959) 3049. 